\title{
REPRESENTAÇÕES SOCIAIS E MAPAS AFETIVOS: VIVÊNCIAS JUVENIS NA ESCOLA PÚBLICA
}

\author{
SOCIAL REPRESENTATIONS AND AFFECTIVE MAPS: \\ YOUTH EXPERIENCES IN PUBLIC SCHOOL \\ REPRESENTACIONES SOCIALES Y MAPAS AFECTIVOS: \\ EXPERIENCIAS JUVENILES EN LA ESCUELA PÚBLICA
}

\author{
Francisca Denise Silva Vasconcelos ${ }^{\mathrm{I}}$ \\ Luana Paiva Da Silva ${ }^{\mathrm{I}}$ \\ Jorge SAmuel de Sousa Teixeira ${ }^{\mathrm{I}}$ \\ Bárbara ElLEN Viana SALES ${ }^{\mathrm{I}}$ \\ Gracymara Mesquita SeVERIano ${ }^{\mathrm{I}}$ \\ Juliana Maria do Nascimento Mota ${ }^{\mathrm{I}}$ \\ ${ }^{\mathrm{I}}$ Universidade Federal do Ceará (UFC), Sobral/CE - Brasil
}

Resumo Este estudo objetivou discutir as Representações Sociais produzidas pelos estudantes a partir do seu ambiente escolar. Para isso, utilizamos o Instrumento Gerador dos Mapas Afetivos com 73 estudantes de uma escola pública de ensino médio da cidade de Sobral. Para a análise dos dados utilizamos como ferramenta o software IRAMUTEQ e a Análise de Conteúdo de Bardin, tendo como base a Teoria das Representações Sociais. Os resultados indicam que as representações construídas pelos estudantes trazem a escola como espaço de sentimentos conflitantes, ora traduzindo um lugar de acolhimento e sociabilidade, e ora revelando um local gerador de sofrimento psíquico através das cobranças reservadas a esses alunos, permeadas ainda pela possibilidade de construção de futuros. Concluímos observando que, embora seja geradora de sentimentos paradoxais, a escola se apresenta como um importante espaço de produção de subjetividades e representações, fruto de criações coletivas e perspectivas individuais que atravessam a juventude nela inserida.

Palavras-chave: Representações Sociais; Escola Pública; Classes Populares; JuVENTUDE.

ABSTRACT This study aimed to discuss the Social Representations produced by students from their school environment. For this, we used the Affective Maps Generating Instrument with 73 students from a public high school in the city of Sobral. For data analysis, we used the IRAMUTEQ software and Bardin Content Analysis as a tool, based on the Theory of Social Representations. The results indicate that the representations constructed by the stu- 
dents bring the school as a space of conflicting feelings, thus translating a place of welcome and sociability, and now revealing a place that generates psychological suffering through the charges reserved for these students, permeated by the possibility of building futures. We conclude by noting that, although it generates paradoxical feelings, the school presents itself as an important space for the production of subjectivities and representations, the result of collective creations and individual perspectives that cross the youth within it.

Keywords: Social Representations; Public School; Popular Classes; Youth.

Resumen Este estudio tuvo como objetivo discutir las Representaciones Sociales producidas por los estudiantes de su entorno escolar. Para ello, utilizamos el Instrumento Generador de Mapas Afectivos con 73 alumnos de un colegio público de la ciudad de Sobral. Para el análisis de datos utilizamos el software IRAMUTEQ y el Análisis de Contenido de Bardin como herramienta, basado en la Teoría de las Representaciones Sociales. Los resultados indican que las representaciones construidas por los estudiantes traen a la escuela como un espacio de sentimientos encontrados, traduciendo a veces un lugar de acogida y sociabilidad, y otras veces revelando un lugar que genera sufrimiento psicológico a través de las cargas reservadas para estos estudiantes, permeado por la posibilidad de construcción de futuros. Concluimos señalando que, si bien genera sentimientos paradójicos, la escuela se presenta como un espacio importante para la producción de subjetividades y representaciones, resultado de creaciones colectivas y perspectivas individuales que atraviesan los jóvenes dentro de ella.

Palabras Clave: Representaciones sociales; Escuela Pública; Clases Populares; JuVENTUD.

\section{INTRODUÇÃo}

A história da educação pública no Brasil possui um desenvolvimento que nos permite perceber o processo de desigualdade ao qual estamos submetidos há séculos. Por um longo período, as escolas públicas de ensino médio eram restritas aos jovens oriundos das camadas altas e médias da sociedade, os herdeiros, segundo Bourdieu (2011). Todavia, a partir da efetivação da Lei de Diretrizes e Bases da Educação de 1996, que reformulou o ensino médio com o objetivo de expandi-lo e melhorar sua qualidade, temos observado um prolongamento da escolaridade no país e uma maior possibilidade de acesso e permanência de jovens de outros segmentos nessa instituição.

Nesse sentido, a escola passa a ser um espaço múltiplo entre as diversas camadas sociais, promovendo a inclusão e a construção coletiva de afetos. Desse modo, o ambiente escolar consolida um ponto de encontro entre instituição incentivadora de busca pelo conhecimento, e espaço comum de relações afetivas. Porém, não devemos deixar de ressaltar que, ainda que sua expansão tenha auxiliado às camadas populares no acesso ao ensino básico, não conseguiu extinguir o processo iníquo enraizado na sociedade atual. Assim, vemos no contexto da modernidade uma divisão entre o público e o privado, que envolve tanto embates econômicos quanto sociais.

Nosso foco, então, volta-se para a escola pública e seu modelo moderno quanto à forma de construção das diversas identidades sociais, tendo como personagens principais 
desse embate, aqueles que estão inseridos no contexto escolar e que são agentes na construção dessa modernidade: os jovens. Dessa maneira, trata-se de considerar a maneira como estes jovens estão inseridos na lógica capitalista e, ao mesmo tempo, como resistem a ela.

Nesse sentido, é notória a importância da compreensão dessa categoria juventude e por que ela influencia fortemente no entendimento do desenrolar desse processo sistemático. De acordo com Rossi (2014), o conceito da juventude permanece em uma constante transformação através do tempo. Porém, seu entendimento durante a modernidade esteve sempre atrelado ao breve período de transição entre a infância e a adultidade, tendo como principais características desta fase, um momento de irresponsabilidade, rebeldia e incerteza (SOUZA, 2004). Nesse contexto, nos deparamos com um sujeito que, inserido em uma lógica capitalista, não está adequado às expectativas socialmente construídas (MARTINS, 2008).

Entretanto, para além do conceito formado no período moderno sobre ser jovem, atualmente compreendemos esta categoria como diversa, que se expande em diferentes grupos e produz distintas representações da realidade. Num contexto escolar, por exemplo, essa diversidade se apresenta na formação de grupos a partir da identificação desses jovens entre si e da criação de vínculos afetivos (SOUZA, 2004).

A escola torna-se, então, um ambiente de expressivo paradoxo, pois, se por um lado ela promove esse encontro da multiplicidade e da emancipação e autonomia dos estudantes, por outro permanece a ser espaço legitimador de desigualdades e da elaboração de formas que mantêm o processo meritocrático em vigor (BOURDIEU, 2011).

Nessa continuidade, partindo da reflexão desse complexo constituinte do espaço escolar apresentado até aqui, toma-se, então, o instigante questionamento sobre a elaboração dos significados da realidade destes jovens inseridos na escola pública. Ademais, consideramos a importância da centralidade do sujeito (jovem) e sua singularidade no que se refere à particularidade de suas significações. Assim, tomando como processo essa elaboração dos sentidos produzidos por esses jovens a partir do espaço escolar, podemos tratar de um fenômeno de interpretação e elaboração de sentidos, apresentado por Moscovici (2007) como Teoria das Representações Sociais (TRS).

A TRS, introduzida por Serge Moscovici, surgiu a partir do interesse desse autor em explorar a variedade de produções ideais coletivas num contexto moderno, criadas a partir da linguagem e das relações intersubjetivas (MOSCOVICI, 2007), ela nos auxilia na compreensão da formação de conhecimento e das relações de interesse dos sujeitos. Assim, seu conceito transpassa neste trabalho de modo a ser um facilitador para a investigação dos sentidos produzidos por esses jovens através da comunicação entre si e com a instituição escolar, e esclarece o resultado que esse processo de significação exerce nesses estudantes.

Partindo dessa constatação, estabelecemos como objetivo a investigação e o esclarecimento das Representações Sociais produzidas por estudantes de escola pública sobre esse ambiente institucional, tomando como base a relação entre escola, juventude, modernidade. Com essa finalidade, utilizamos como ferramenta facilitadora o Instrumento Gerador de Mapas Afetivos (IGMA), que nos permitiu a criação de um espaço de diálogo entre alunos secundaristas e pesquisadores, e auxiliou o processo de compreensão e mapeamento das associações geradas pelos sujeitos em relação ao ambiente escolar. 


\section{A teoria das representações sociais: um ponto de partida}

Serge Moscovici foi o responsável por trazer à tona os fundamentos que dão base à Teoria das Representações Sociais (TRS). O escritor traz como pontapé inicial a integração do social e do psicológico, na tentativa de criar uma ciência mista que partisse do conceito de representação. Com isso em mente, podemos afirmar que sua pretensão de reunir em uma mesma ciência pressupostos que dessem conta das dimensões individuais e sociais representou uma cisão junto aos pensadores clássicos. Os pontos de divergência com Durkheim, por exemplo, representam muito bem esses contrapontos (MOSCOVICI, 2007).

Émile Durkheim defende a ideia de uma separação de disciplinas no estudo dos fenômenos coletivos e individuais. Para o autor, as representações individuais seriam objeto de estudo da ciência psicológica, enquanto as representações coletivas ficariam a cargo da Sociologia. Durkheim chega mesmo a afirmar em seu aforismo que sempre que um fenômeno social é explicado por intermédio de um fenômeno psicológico, estaríamos trabalhando com uma explicação falsa. Nesse sentido, Moscovici se contrapõe a esses ideais ao trabalhar com representações constituídas a partir de crenças coletivas, que são variadas, diversificadas e dinâmicas, se distanciando da ideia de Representações Coletivas, estruturadas de forma mais cristalizada, fixa e estática, e mais avessa a mudanças de perspectivas. Portanto, Moscovici vai trabalhar com o pensamento de que vemos as mesmas coisas, mas as vemos da nossa maneira (MOSCOVICI, 2007).

A TRS então, concebe a ideia de pessoas e grupos que pensam por si mesmos, que constroem, produzem e comunicam suas próprias representações. Nesse contexto, a ciência, as ideologias, os meios de comunicação e as diversas formas de mídia serviriam apenas como um "alimento para o pensamento" desses indivíduos (MOSCOVICI, 2007, p. 45), mas não seriam ferramentas capazes de moldar completamente a maneira como representamos os fenômenos sociais.

Assim, o autor, ao elaborar sua teoria sobre as Representações Sociais, busca trabalhar com as mudanças e inovações sociais, visto que, o projeto de sua Psicologia Social é exatamente orientada para como as coisas mudam na vida em sociedade, e é esse caráter fluido presente nas explicações do mesmo que não permitem entender as representações como algo dado nem como meras variáveis explicativas, mas como processos passíveis a mudança, a depender da visão do observador (MOSCOVICI, 2007).

Assim, o propósito de toda representação vai ser tornar algo não familiar em algo familiar. Isso porque aquilo que é desconhecido nos assusta e causa estranheza. As representações, então, teriam como objetivo exatamente estabelecer um significado para determinados fenômenos que não nos são familiares. Para tanto, com o intuito de representar aquilo que é desconhecido, fazemos referência ao que já conhecemos, até que se chegue a um ponto onde esse não familiar se torne normal e até comum para nós (MOSCOVICI, 2007).

Para que o propósito supracitado seja alcançado, dois processos são os responsáveis pela geração das Representações Sociais: a ancoragem e a objetivação. A primeira é uma tentativa de enquadrar essas ideias estranhas, reduzindo-as a imagens comuns ou até mesmo categorizando-as, buscando localizá-las dentro de um contexto familiar ao indivíduo. Já o segundo mecanismo objetiva essas ideias, isto é, transpõe do abstrato à forma mais concreta possível, externalizando aquilo que está na mente para o universo físico. São essas 
duas ferramentas as responsáveis por transformar o não familiar em algo familiar, já que primeiro ancoramos essas ideias, por meio de comparações e interpretações, para depois objetivá-las, reproduzindo o desconhecido em coisas tangíveis, que podemos ver, tocar, e até mesmo controlar, já que as representações nada mais são do que conhecimentos práticos capazes de conectar o sujeito a um objeto (MOSCOVICI, 2007; JODELET, 2001).

Entendendo, então, que as Representações Sociais possibilitam ao sujeito exprimir suas significações à suas experiências no mundo social, e projetar valores e aspirações sociais (JODELET, 1990), o ambiente escolar aparece como um local capaz de gerar uma diversidade de representações por aqueles que lhes constituem. Como já citado por Moscovici (1990) ao fundir as dimensões social e psicológica dentro de sua teoria científica, para se fazer uma pesquisa educacional que produza um maior impacto sobre as práticas educativas, tanto é necessária a postura de um olhar psicossocial que dê conta das especificidades do sujeito, quanto uma perspectiva que restitua esse indivíduo também ao mundo social.

Portanto, considerando que a Teoria das Representações Sociais estabelece inúmeros vínculos com pontos fundamentais para se adentrar no campo escolar, tais como a linguagem, a ideologia, as questões que cercam o imaginário social, e, sobretudo, sua função embutida na orientação das condutas e práticas sociais (ALVES-MAZZOTTI, 1994), tal referencial se constitui como essencial quando se está trabalhando com o público da escola, principalmente quando esse público é composto por estudantes que atribuem diferentes significados ao local em que estudam.

\section{Metodologia}

O presente estudo provém das ações realizadas pelo projeto de extensão Reescrevendo Minha História - vinculado ao Laboratório de Estudos das Desigualdades \& Diversidades - LAEDDES, realizadas em outubro de 2019. Essas atividades foram desenvolvidas com estudantes de uma escola de ensino médio pertencente a rede pública do município de Sobral - CE.

A referida escola na qual realizamos essa pesquisa faz parte da rede estadual de educação do Estado do Ceará, no centro de Sobral. O funcionamento da instituição divide-se nos três turnos: matutino e vespertino são ocupados com alunos do $1^{\circ}$ ao $3^{\circ}$ ano, e no turno da noite há o funcionamento do EJA (Educação de Jovens e Adultos). No total, a escola possui uma equipe profissional de 43 pessoas, e atende aproximadamente 550 estudantes, sendo a maioria provenientes de bairros periféricos de Sobral com alto índice de violência.

Inicialmente, a equipe pedagógica da escola foi contatada para que os extensionistas apresentassem a proposta de intervenção a ser realizada. A partir do aceite da instituição, elaboramos um cronograma de visitas para as turmas selecionadas, sendo estas quatro turmas de terceiro ano, totalizando 73 participantes. Todas as atividades foram ministradas por acadêmicos de Psicologia da Universidade Federal do Ceará - Campus Sobral, integrantes do LAEDDES.

As intervenções realizadas corresponderam à aplicação de uma versão adaptada do Instrumento Gerador dos Mapas Afetivos (IGMA), que possibilitou revelar como o ambiente escolar é captado pela subjetividade desse grupo de estudantes, por intermédio de 
desenhos, metáforas e palavras. Sendo esses momentos realizados a partir da divisão das turmas em pequenos grupos de estudantes, tendo os extensionistas como mediadores de cada um deles, de modo a facilitar e aproximar o diálogo entre todos os participantes.

O IGMA é um instrumento elaborado por Bomfim (2003) em sua tese de doutorado como um método de investigação dos afetos em relação ao ambiente. Essa ferramenta é dividida em duas partes, tendo um componente qualitativo, no qual o participante elabora imagens e expressa seus sentimentos por meio da escrita, e uma parte quantitativa, que em nosso caso não foi utilizada, composta de uma escala do tipo Likert.

Em relação aos procedimentos de aplicação, inicialmente estavam disponibilizados materiais como folhas A4, lápis de cor, canetas e lápis para os estudantes. Com isso, pedimos que eles representassem por meio de desenhos a sua forma de ver e sentir a escola. Posteriormente, pedimos que elencassem 6 palavras que expressassem e resumissem o que sentiam em relação a esse espaço. Depois desse momento, iniciamos uma conversa acerca do que foi representado por eles, tendo como perguntas disparadoras: O que significa seu desenho? Que sentimentos ele representa? Que palavras você escreveu? Por quê? Ao final, pedimos para que os jovens escrevessem sua idade e sexo em sua folha, identificando-se através do nome somente caso se sentissem à vontade.

A análise dos dados provenientes da aplicação do IGMA foi realizada com base na teoria das representações sociais (JODELET, 2001; MOSCOVICI, 2007) e da Análise de conteúdo de Bardin (1977), tendo como ferramenta o software IRAMUTEQ (Interface de $R$ pour lês Analyses Multidimensionnelles de Textes et de Questionnaires).

O estudo do conteúdo das representações foi efetuado a partir da análise das palavras produzidas pelos estudantes com auxílio da Análise de Similitude realizada pelo IRAMUTEQ. A Análise de Similitude permite identificar as ocorrências e as indicações da conexidade entre as palavras, auxiliando na identificação da estrutura do conteúdo de um corpus textual (CAMARGO; JUSTO, 2013). Nesse contexto, as palavras foram categorizadas por meio do processo de Análise de Conteúdo de Bardin (1977), contando com as seguintes etapas operacionais: organização, codificação, categorização do material e, por fim, análise e interpretação dos conteúdos temáticos agrupados por categorias, tendo como guia a Teoria das Representações Sociais.

Ademais, o estudo foi aprovado pelo Comitê de Ética em Pesquisa da Universidade Estadual Vale do Acaraú, de acordo com os termos da resolução n. 196/96, sob o número 4.335.384.

\section{RESULTADOS E DISCUSSÃo}

Entendemos que as palavras encontradas na nossa análise são mais que simplesmente palavras, mas discursos proferidos e construídos dentro de contextos sociais específicos (BARDIN, 1977), e que, portanto, atravessam o ambiente escolar. Assim, seguem os resultados da análise da estrutura das representações sociais identificadas, que resultou nos temas: "A Escola como espaço de amizade e acolhimento"; "As cobranças do ambiente escolar"; e "A escola como caminho para o futuro". 


\section{Minha escola, minha vida: sobre afetos e acolhimento no ambiente edu- cacional}

Buscamos explorar, pela análise das Representações Sociais da escola, as diversas posições que esses jovens podem assumir diante desse objeto, ou seja, os diferentes significados e formas de visualizá-lo. Um dos aspectos mais importantes observados a partir dos discursos produzidos pelos estudantes é a importância atribuída por eles às interações sociais no âmbito escolar. O destaque tido pela palavra "Amizade" (frequência: 12), que se ramifica em "Amor" (frequência: 6), "Alegria" (frequência: 5), "Vida" (frequência: 3), "Força" (frequência: 4) e "Liberdade" (frequência: 4), nos permite compreender que para esses jovens, a escola se constitui como um espaço de acolhimento e de desenvolvimento dos seus vínculos socioafetivos. Partindo da Análise de Conteúdo, que objetiva inferir conhecimentos sobre o emissor da mensagem, seu meio e as condições de produção das suas falas (BARDIN, 1977), podemos tecer considerações acerca dos contextos que se relacionam com a produção das falas desses estudantes.

Inicialmente, consideramos que é importante situar o lugar social desses jovens, o que contribui para refletirmos sobre os limites e possibilidades que estarão vinculados com a forma como esses estudantes constroem suas representações. A vivência da juventude nas classes populares carrega desafios consideráveis, posto que a "dupla condição" ("condição" de jovem e "condição de pobre") que atravessa essas pessoas interfere diretamente na trajetória de vida e nas possibilidades e sentidos produzidos pelos mesmos, numa tensão contínua entre a busca pela sobrevivência imediata e um possível projeto de futuro (DAYRELL, 2007). Sendo, portanto, uma juventude que conta com menos recursos e possibilidades de escolha.

Portanto, o tema da identidade aparece como fundamental, porque essa fase, ao ser comumente definida como de transição e busca pela idade adulta, remete para os jovens (quer individualmente ou em grupo) a questão da busca pelo autorreconhecimento e por ser reconhecido pelos demais (DAYRELL, 2007). Entretanto, ao nos referirmos ao universo juvenil, sabemos que este momento da vida humana está carregado de representações, na maioria das vezes encobertas de estereótipos e preconceitos, principalmente se considerarmos a questão da classe e da inserção na escola pública. Pensando com Moscovici (2007), entendemos que as Representações Sociais dão formas e significados para objetos, pessoas e acontecimentos, determinando modelos que serão partilhados por determinados grupos de pessoas. Assim, o que temos como imagens dessa juventude pobre, quase sempre elaboradas a partir de produções midiáticas, seriam, além de um "vir a ser", projetado para o futuro, o marcante atributo da violência e da marginalidade (DAYRELL, 2007; SPOSITO, 1996).

Nesse sentido, esses estereótipos acabam por atribuir determinadas características a priori nesses sujeitos, fazendo com que neguemos o direito de fala desses jovens, ao considerarmos que são incapazes de produzirem sentidos a partir de si mesmos, e que as definições que lhe são atribuídas são as suas próprias definições (SPOSITO, 1996). Trazendo a discussão sobre lugar de fala, compreendemos que a juventude pobre da escola pública se constitui como um grupo de sujeitos atravessados por um lugar social e por uma matriz de dominação que impede que esses estudantes tenham acesso aos espaços discursivos privilegiados (RIBEIRO, 2017). Isso posto, muitas vezes essas representações são, de fato, 
incorporadas pelo jovem no seu processo de autorreconhecimento, deformando sua identidade (SPOSITO, 1996).

Diante dessas representações e estigmas, o jovem pobre tende a ser visto na perspectiva da incompletude e da desconfiança, sendo, entretanto, pertencente a um "contingente da população a quem se retirou o direito de projetar o futuro, apresentando somente o não-emprego, o não-salário, a ausência de direitos e de espaços de convivência cultural como alternativas de vida" (SPOSITO, 1996, p. 100). Partindo disso, a escola também será um espaço que "tende a não reconhecer o 'jovem' existente no 'aluno', muito menos compreender a diversidade, seja étnica, de gênero ou de orientação sexual, entre outras expressões, com a qual a condição juvenil se apresenta" (DAYRELL, 2007, p. 1117). Apesar disso, essa instituição é invadida pelas diversidades, dilemas e desafios da vida juvenil, constituindo-se também como um espaço para os amores, as amizades e as angústias que atravessam esses sujeitos.

À vista disso, o cotidiano escolar aparece como um espaço complexo de interações entre os estudantes, com demarcação de identidades e a formação de diferentes grupos. Com base nos relatos obtidos a partir das nossas ações de extensão, percebemos que muitas vezes as relações entre os alunos ganham mais importância do que as próprias regras escolares, constituindo-se em uma referência determinante na construção dos sentidos elaborados por esses jovens em relação ao ambiente escolar. No caso dos jovens pobres, a sociabilidade na escola ganha ainda maior dimensão, posto que em meio a territórios marcados pela ausência de equipamentos públicos de cultura e lazer, as expectativas de produção de relações entre os pares recaem principalmente sobre essa instituição (DAYRELL, 2007; SANTOS; NASCIMENTO; MENEZES, 2012).

A experiência social da juventude contemporânea está imersa em angústias e incertezas, geradas principalmente por questionamentos acerca de qual seria seu lugar social. Assim, esse momento da vida é marcado pelo estreitamento dos laços com seus pares em detrimento das figuras familiares, posto que a busca por apoio, identificação, autoestima, intimidade e compartilhamento de experiências, faz com que esses sujeitos se aproximem daqueles que possivelmente também compartilham de situações, desafios e dúvidas semelhantes (PEREIRA; GARCIA, 2007; PERON; GUIMARÃES; SOUZA, 2010; SCHWERTNER, 2012; SOUZA, 2004). Desse modo, os grupos de amizade formados por esses jovens são fonte de entretenimento, afeto, acolhimento e segurança, palavras que muitos apareceram nos Mapas Afetivos dos sujeitos participantes das ações.

Mas o que seria então esse fenômeno da amizade? Por meio da TRS entendemos que os objetos são carregados de significações e interpretações que atravessam os diferentes grupos sociais (JODELET, 2001; MOSCOVICI, 2007). Por esse ângulo, a amizade também se constitui como um fenômeno social contextualizado cultural e historicamente, apesar disso, entendemos que algumas características se apresentam como fundamentais em diferentes contextos: uma interação diádica, pessoal, recíproca, informal e íntima, iniciada por livre escolha e sustentada por um forte componente afetivo (PEREIRA; GARCIA, 2007; PERON; GUIMARÃES; SOUZA, 2010).

As amizades desempenham, portanto, um importante papel na vida dos adolescentes, se relacionando diretamente com suas vivências escolares. São relações que promovem apoio 
social e emocional e colaboram para a manutenção da saúde física e mental desses indivíduos, principalmente se levarmos em conta uma juventude marcada por desigualdades, vulnerabilidades e angústias. Assim, o apoio provido pelos amigos se torna fundamental em diferentes âmbitos da vida desses sujeitos, tais como na proteção contra sentimentos de angústia social, na moderação do impacto de problemas familiares, e até mesmo como forma de desenvolver uma aprendizagem realmente significativa (PEREIRA; GARCIA, 2007).

Enfim, podemos compreender que as amizades construídas no ambiente escolar, para os jovens participantes, parecem responder às suas necessidades de comunicação, de acolhimento, de autonomia, de trocas afetivas, de identidade, de afirmação diante do mundo adulto, e de reivindicação de direitos (DAYRELL, 2007; SANTOS; NASCIMENTO; MENEZES, 2012). Baseados na análise dos mapas afetivos, acreditamos que a escola acaba por, na maioria das vezes, negar a oportunidade de fala, de construção de identidades, e de autonomia de seus estudantes. Mesmo assim, através da representação da escola como espaço de amizade, - modo de torná-la familiar e objetivar os sentimentos que se tem ao se olhar para ela -, entendemos que esses jovens conseguem entre pares vivenciar momentos de sociabilidade e de trocas significativas, seja nos intervalos entre as aulas, nos deslocamentos até a escola, ou até mesmo nos próprios corredores e salas de aula, que acabam se constituindo como momentos e espaços de liberdade. Assim, mais do que "ensinar coisas" e "vender futuros", a escola também os "acolhe e abraça".

\section{Minha escola, meus resultados: sobre medos e cobranças do ambiente escolar}

O ambiente escolar, como o conhecemos hoje, apresenta-se como um espaço de diversas possibilidades na criação de relações afetivas e na troca de conhecimento que surgem a partir dessas interações. Podemos considerar, ao adentrar na escola, que existe uma espécie de "rede" dessas relações, construída a partir das diversas manifestações da linguagem entre os sujeitos que nela estão inseridos.

Porém, para além desse espaço que possibilita contato, a escola também não se pode negar enquanto instituição preparatória antecedente ao mercado de trabalho, que estabelece nessa construção de sociabilidade interpessoal a formação necessária a esses jovens para os futuros contatos gerados no espaço laboral.

Muito se é discutido sobre os diferentes modos que as escolas aderem nesse processo de "preparação para a fase adulta" e, mais importante que isso, os impactos - físicos e emocionais - que esses diversos meios causam nos estudantes. Logo, nos parece extremamente necessário que esses sentimentos apresentados pelos estudantes sejam explorados de modo a tentarmos compreender as dimensões desse impacto no processo "preparatório para o futuro" sofrido por jovens de escola pública.

Diante de um contexto capitalista, não surpreende que a instituição escolar esteja inserida nesse processo de formação de futuros trabalhadores, tendo como principal função a qualificação de base desses sujeitos. Podemos perceber também, a partir de Souza (2003), que existe um objetivo inerente a esse esforço mostrado pelos estudantes em conseguir êxito escolar, sua dimensão gira em torno da conquista de ascensão social através do estudo e/ ou do trabalho e sua inclusão no reconhecimento enquanto "gente" em meio social. 
Dessa forma, refletindo sobre esse contexto, podemos considerar o conceito apresentado por Souza (2003) de ideologia do desempenho, baseado numa tríade meritocrática que engloba qualificação, posição e salário - como forma de explicar o vislumbre da ascensão social por esses estudantes de classes populares. Esse conceito utilizado pelo autor nos ajuda a esclarecer os possíveis motivos da escolha de palavras apresentadas pelos alunos e que dão forma a esta discussão.

Trabalharemos, então, a partir das seguintes palavras: "pressão", "insegurança", "cobrança", "dificuldade", "angústia", "ansiedade", "medo", "cansaço" e "vagabundo", que compõem uma parte dos dados analisados pelo software IRAMUTEQ e que se apresentam interligadas nos resultados do programa com base nos escritos dos estudantes. Entretanto, ressaltamos novamente que essas palavras trabalhadas ao longo de todo este artigo não devem ser consideradas apenas substantivos, mas discursos preenchidos de significados por aqueles que os sentenciam.

Como já citado, a escola tem uma "dupla face" frente às organizações afetivas dos estudantes, tanto é um lugar acolhedor e promotor de relações quanto um espaço de cobranças sobre os alunos frente a um contexto capitalista. Em vista disso, pensando no que Moscovici (2007) nos traz sobre a Teoria das Representações Sociais, compreendemos que os modos de entendimento dos acontecimentos ao nosso redor são, simultaneamente, singulares e sociais e estão presentes nos diálogos e interações que esses estudantes têm com o espaço escolar.

Nesse sentido, concordamos com Osti e Brenelli (2013), quando discutem essas relações afetivas na escola e as representações feitas pelos estudantes a partir dessas interações. As autoras nos esclarecem que as representações não são inatas, mas construídas a partir de uma rede de relacionamentos do sujeito com o ambiente e que, a depender das representações criadas, podemos perceber um quadro de sucesso ou fracasso escolar. Essa questão pode surgir a partir do sentimento de pertencimento dos alunos, que por sua vez está atrelado ao processo de identificação presente nos relacionamentos em grupo dentro da escola (OSTI; BRENELLI, 2013).

Ademais, também devemos lembrar que a escola possui uma segunda faceta enquanto instituição preparatória de jovens trabalhadores. Destacamos esse fato pois nas palavras apresentadas pelos alunos, muitas, senão todas, possuíam como foco o sentimento de obrigação frente ao sucesso escolar, porém essa obrigatoriedade resultava numa sensação negativa junto à instituição. Os alunos destacaram "medo" e "cobrança" como palavras mais recorrentes em seus discursos, tendo como frequência de repetições dez e nove vezes, respectivamente. Compreendemos, então, que esse contexto se liga a uma constante tentativa desses jovens provenientes de classes empobrecidas de modificarem seu status social através do estudo, consequentemente do sucesso financeiro, e poderem se perceber enquanto "gente", perspectiva que lhes é improvável frente a um complexo processo de incorporação da ideia do "lugar do pobre" (PIOTTO, 2009; PIOTTO, 2010).

O sentimento de cobrança e pressão apareceriam nesse contexto de responsabilidade do jovem, nos confirmando o que Bourdieu (1983) e Pais (1990) relatam sobre a visão da juventude como sujeitos sem estabilidade financeira e emocional, e que para conseguir ultrapassar essa fase da juventude o sujeito recorreria ao estudo ou ao trabalho, como 
formas de obter êxito em sua passagem para a adultidade, deixando para trás a ideia de "vagabundo", uma das palavras presentes nos escritos dos estudantes.

Devemos nos atentar, porém, para a recorrente desigualdade que nos assola em questão de educação pública e privada e as oportunidades de mudanças desses contextos, não esquecendo da relação meritocrática apresentada por Souza (2003) na teoria da ideologia do desempenho. Tal conceito nos esclarece sobre a possibilidade de mudança de um contexto social a partir do, assim dito, esforço, atribuindo ao sujeito seus méritos frente às suas conquistas. $\mathrm{O}$ autor, entretanto, critica esse posicionamento, traduzindo a posição de desigualdade à qual essa ideologia nos sujeita, desconsiderando os pontos de partida desses jovens com relação aos estudos, o que refletiria em um espaço de grandes iniquidades. Com relação a essas desigualdades, Bourdieu (2011, p. 41) aponta: "ora, vê-se nas oportunidades de acesso ao ensino superior o resultado de uma seleção direta ou indireta que, ao longo da escolaridade, pesa com rigor desigual sobre os sujeitos das diferentes classes sociais".

Assim, se torna menos complexo compreendermos a existência de um sistema de seleção desigual quanto ao ensino superior e ao mercado de trabalho, que influencia diretamente na produção de significados e nas atitudes frente à escola por esses alunos. Para corroborar essa discussão, nos utilizamos das próprias palavras dos estudantes resultadas dos mapas afetivos, destacando "dificuldade", "insegurança" e "cansaço", que tiveram como frequências três, quatro e seis vezes, respectivamente. Ademais, é importante destacar que "insegurança" e "cansaço" aparecem na análise de similitude ligados diretamente a "medo" e "cobrança", e "dificuldade", assim como "vagabundo" se ramifica da palavra "cobrança" no resultado do programa IRAMUTEQ.

Dessa forma, a partir de toda a discussão feita até aqui, podemos também compreender os sentidos das palavras "angústia" (frequência de seis vezes) e "ansiedade" (frequência de oito vezes) frente a esse cenário desmotivador da educação de jovens provenientes das camadas populares, visto que, principalmente para estudantes do terceiro ano do ensino médio, muitas vezes conhecidos como "pré-universitários" ou "pré-vestibulandos" (expressões que em si já produzem sentidos de um futuro próximo, inadiável e indiscutível), a escolha profissional é causadora de sentimentos conflitantes, principalmente se considerarmos que cursos diferentes possuem seletividades diferentes (SOARES; MARTINS, 2010).

Por fim, diante das palavras escolhidas por esses estudantes, percebemos uma constante inquietação quanto ao ambiente escolar, que já não se vê aqui enquanto espaço acolhedor, mas produtor de significados negativos e de angústias, o que reflete também sobre as representações desses jovens quanto a educação e principalmente ao ensino público, dificultando seus objetivos iniciais de êxito econômico e de inclusão social e traduzindo seu processo de familiarização com a escola em adoecimento físico e emocional.

\section{Minha escola, meu futuro: sobre as incertezas das trajetórias de jovens pobres}

Durante a aplicação do Instrumento Gerador de Mapas Afetivos (IGMA), as referências a palavras como "futuro", "sucesso", "esperança", "orgulho", "aprendizado" e "felicidade" constituíram mais uma categoria de análise, gerada a partir dos levantamentos feitos no software IRAMUTEQ. A escola enquanto instituição capaz de promover ou pelo menos 
direcionar esses estudantes a um futuro ainda desconhecido para eles aparece aqui enquanto um espaço quase preparatório, cuja função seria abrir as portas do mercado de trabalho para esses indivíduos.

Os modos de vivência da juventude na atualidade se transformam juntamente com as mudanças ocorridas na sociedade, não sendo mais possível estabelecer os mesmos padrões que caracterizariam essa fase da vida há décadas atrás. Nesse ínterim, Camarano (2006) cita as relações de trabalho e a exigência de uma escolaridade mais elevada como fatores que afetam essas vivências na dimensão pública. Seguindo essa linha de raciocínio, era de se esperar que as pressões impostas a esse público dentro de uma coletividade moderna fossem cada vez mais presentes, sobretudo por se tratar de um público que passa do ápice da pirâmide do ensino básico para a base da pirâmide mercadológica.

Utilizando a análise de conteúdo como ferramenta para entender esse contexto, Bardin (1977) afirma que a mesma tem como intenção a inferência dos conhecimentos relacionados à condição de produção e que recorre a indicadores, sejam eles quantitativos ou não. Essas inferências serão capazes, então, de elucidar duas questões primordiais: os antecedentes de um determinado enunciado e as consequências provocadas por ele. Nesse contexto, uma escola como promotora de um porvir capaz de proporcionar a seus alunos maiores doses de esperança e felicidade ancoradas na promessa de um futuro bem-sucedido é um discurso que tem como antecedente, sobretudo, o avanço dos ideais modernos, que encontram abrigo dentro do sistema capitalista, e que causa efeitos na maneira como esses jovens constroem suas formas de significar o ambiente escolar, além de atingir em cheio a dimensão psicossocial desse público.

É, então, importante ressaltar que os termos empregados pelos estudantes para fazer referência ao local onde estudam são produtos de uma construção social, que é atravessada por discursos e ideias, bem como pelo contexto vivenciado pelos mesmos. Assim, como afirma Bardin (1977), verificar as unidades de contexto em que são produzidos tais conteúdos é fundamental na tarefa de compreender a significação exata dessas unidades de registro, levando em consideração, principalmente, que não tratamos nesse artigo com palavras soltas, mas com caracteres que são representativos daquilo que os participantes vivenciaram, vivenciam e representam socialmente.

O caminho apontado pelos secundaristas encontra aqui um sentido específico. Durante as atividades da extensão, foi possível perceber que os mesmos relacionam esse termo a uma trajetória que parece já estar devidamente construída pela instituição escolar, isto é, um percurso pré-definido, cabendo a esses jovens a mera missão de segui-lo. A escola passa a também agir como um dispositivo de controle, tendo papel fundamental na constituição da subjetividade dos alunos (SARAIVA; VEIGA-NETO, 2009). Por conseguinte, o futuro desses jovens vai ser constantemente atrelado à maneira que eles encontram de significar a ideia de futuro que é produzida pela instituição.

A ideia de projeto de vida também encontra seu lugar dentro dessa discussão. O mesmo pode ser considerado como uma meta de vida a ser atingida em um longo prazo, sendo esse objetivo orientado exatamente para o futuro, e possuindo um significado para o sujeito que possa servir como um motor motivador à existência dessa pessoa (MARIANO; SAVAGE, 2009). A constituição desses projetos inevitavelmente parte de fatores constituintes 
da subjetividade desses sujeitos, dos estímulos ambientais que o circundam, além, é claro, dos discursos que envolvem seus futuros em particular. Assim, um projeto de vida voltado à caminhos que podem ser proporcionados pela educação são possíveis dentro da perspectiva dos secundaristas, que associam palavras como sucesso e esperança (ambas citadas 5 vezes, cada) à essa etapa pós vida escolar.

Fernandes (2003) traz ainda a dimensão da dupla associação feita por estudantes entre processo de escolarização e futuro. "A garantia de um futuro melhor" enquanto máxima quase universal dos benefícios proporcionados pela educação é desmistificada pelo autor, que afirma que mesmo com futuro garantido, os jovens entrevistados em sua tese continuariam seus estudos, destacando principalmente o, por assim dizer, passaporte para o mundo do trabalho proporcionado pelos conhecimentos adquiridos na idade escolar. Consequentemente, o saber que é repassado no presente acaba gerando consequências no futuro daqueles atingidos por esses conhecimentos. A escola enquanto promotora do futuro pode até contribuir para a lógica capitalista moderna, mas seria inviável não a considerar também enquanto uma via de oportunidade para aqueles oriundos de classes populares economicamente e socialmente desfavorecidos. Não à toa, a palavra "felicidade" foi encontrada 7 vezes durante a análise dos mapas.

Nesse âmbito de "produções de futuros", a ideologia do desempenho parece ganhar notória importância como artifício de elaboração desses percursos, o que pode ser notado a partir da repetição do termo "futuro" por 4 vezes nas produções dos alunos. Como supracitado, Souza (2003) caracteriza a mesma dentro de um discurso calcado em um pensamento meritocrático baseado em três pilares principais, a saber, a qualificação, a posição e o salário. Inegavelmente, as bases constituintes dessa ideologia envolvem-se intimamente ao universo conhecido como mercado de trabalho. As posições hierárquicas observáveis dentro dos contextos trabalhistas aparecem desde cedo no cotidiano dos secundaristas, a começar pela legitimação do acesso diferencial a determinadas chances de vida, como cita o autor. $\mathrm{Na}$ própria escola, aqueles que obtém um desempenho considerado satisfatório perante o crivo de avaliações da instituição são recompensados com certos benefícios, enquanto aqueles com performances consideradas insatisfatórias ou medianas são posicionados a escanteio e tornam-se coadjuvantes no cenário de qualificações que o ambiente escolar pode proporcionar.

As representações da escola por parte dos alunos, desse modo, atravessam esse contexto e se constituem com base nos enunciados modernos propagados sobre esse ambiente. Assim, esse olhar que aponta para a escola como uma preparação para o futuro está ancorado na ideia de que a mesma é capaz de prover as diretrizes fundamentais para a trajetória pós-ensino médio dos discentes, um pensamento que, nesse ponto, associa-se à noção de ancoragem desenvolvida por Serge Moscovici ao elaborar sua Teoria das Representações Sociais. Segundo o autor, ao gerar as representações sociais, primeiro enquadramos ideias estranhas, reduzindo-as a categorias e imagens comuns, para que as mesmas nos sejam apresentadas em um contexto mais familiar (MOSCOVICI, 2007). Partindo disso, a escola rotulada como um espaço que pode alavancar sua trajetória profissional torna o ideal "escola" enquadrada em certos princípios que vendem a ideia do sonho capitalista moderno.

A modernidade, então, entra em jogo nesse contexto, principalmente por meio das manifestações do capital, revelando-se cada dia mais difusas e globalizadas e alterando a 
lógica exploratória do trabalhador. Se antes elas se limitavam ao ambiente fabril, colocando duas classes em oposição, constituindo um antagonismo, hoje essas manifestações estão fragmentadas em diversos interesses polarizados e incompatíveis (MARTINS, 2008). O sistema moderno, aliado ao capitalismo, contribui dessa forma para a manutenção de uma representação de escola pautada em uma perspectiva voltada para o que ainda está por vir. E de tanto centralizar o futuro, esse foco acaba, muitas vezes, ignorando o presente e a subjetividade daqueles que constituem a instituição escolar, sobretudo os alunos. Recortando esse olhar para a educação pública, as conotações negativas trazidas nos mapas pelos estudantes fazem sentido à medida que lidamos com um público cujo presente em um contexto empobrecido dificulta a missão de olhar para um futuro que, muitas vezes, é constituído sem muitas expectativas. Ao se opor a essa espécie de planejamento, os estudantes atribuem à essa escola termos que fazem referência a, talvez, o único local capaz de lhes dar possibilidades de sucesso e esperança no futuro.

Isto posto, a instituição escolar se configura como um lugar capaz de gerar um paradoxo que confunde conotações positivas e negativas naqueles que a constroem, isso é, os alunos. Ao mesmo tempo que ela pode representar a principal oportunidade de romper um ciclo vicioso e familiar que tem como consequência condições socioeconômicas vulneráveis, a mesma também pode ser representada enquanto promotora de diretrizes para um futuro que nem sempre é desejado por esses secundaristas. Dentro dessa dualidade, as palavras utilizadas para representar o local em que estudam são fruto de um contexto e de uma história pessoal de cada um, mostrando que as formas de criação coletiva também podem ser diferentes, com base nas perspectivas individuais (MOSCOVICI, 2007).

\section{CONSIDERAÇões FINAIS}

A partir das representações produzidas pelos estudantes acerca do seu ambiente escolar, pudemos compreender que a escola representa um espaço de sentimentos conflitantes, que ora traduz um lugar de acolhimento, e ora revela um local gerador de sofrimento psíquico através das cobranças reservadas a esses alunos. Com relação aos sentimentos positivos, ficou claro que a escola envolve em sua completude as relações afetivas entre grupos de amizade, e que dentro desses grupos os estudantes se encontram em um processo de identificação, que os ajuda a perceber o ambiente escolar como espaço libertador. Entretanto, com relação aos sentidos negativos, observou-se críticas quanto às cobranças exercidas pela instituição, que eram causadoras de sentimentos estressores, como medo, insegurança e ansiedade.

Ademais, também elaboramos, a partir do retorno dado pelos estudantes em relação ao ambiente escolar, a noção de "futuro" que compõe os sentidos presentes nos discursos e que percebemos estar relacionada, diretamente, com uma imagem de sucesso almejada por esses jovens. Dessa forma, compreendemos que há dentro da escola pública processos de construção de significações, que se manifestam a partir da relação dos sujeitos com o ambiente escolar.

A dualidade representada pelas palavras escritas nos mapas afetivos demonstrou ainda que as especificidades de cada indivíduo precisam ser levadas em conta, sobretudo quando 
se trabalha com pessoas cujas subjetividades exercem forte impacto dentro das relações sociais. Professores, diretores, coordenadores e a diversidade de funcionários que compõem o corpo escolar são ancorados sob uma base formada por alunos que necessitam de uma atenção maior voltada à dimensão do pessoal, daquilo que lhes constitui enquanto sujeito $\mathrm{e}$ daquilo que pode ser gerador de sofrimento ético-político para os mesmos.

Destarte, é importante destacar que não traçamos como um objetivo almejado desse artigo o encerramento das discussões que envolvem a escola e a forma como a mesma é representada pelos secundaristas. Devido à diversidade de maneiras que essa instituição pode ser retratada pelos estudantes, é necessário que mais estudos que busquem investigar essa construção social do ambiente escolar sejam realizados, com o intuito de colocar cada vez mais em voga a centralidade embutida na constituição da subjetividade daqueles que constroem e reconstroem aquilo que conhecemos pelo nome de escola.

\section{REFERÊNCIAS}

ALVES-MAZZOTTI, A. Representações sociais: aspectos teóricos e aplicações à educação. Em aberto, v. 14, n. 61, p. 60-78, jan./mar. 1994.

BARDIN, L. Análise de Conteúdo. Lisboa: Edições 70, 1977.

BOMFIM, Z. Á. C. Cidade e afetividade: estima e construção dos mapas afetivos de Barcelona e de São Paulo. Tese (Doutorado em Psicologia) - Pontifícia Universidade Católica de São Paulo, São Paulo, 2003.

BOURDIEU, P. Escritos de Educação. Petrópolis, Rio de Janeiro: Vozes, 2011.

BOURDIEU, P. Questões de sociologia. Rio de Janeiro: Editora Marco Zero Limitada, 1983.

CAMARANO, A. A. Transição para a vida adulta ou vida adulta em transição?. Rio de Janeiro: IPEA, 2006.

CAMARGO, B. V.; JUSTO, A. M. IRAMUTEQ: um software gratuito para análise de dados textuais. Temas em Psicologia, Ribeirão Preto, v. 21, n. 2, p. 513-518, dez. 2013.

DAYRELL, J. A escola "faz" as juventudes? Reflexões em torno da socialização juvenil. Educação \& Sociedade, Campinas, v. 28, n. 100, p. 1105-1128, out. 2007.

FERNANDES, D. G. Ir-remediável campo de sonhos de futuro: representações sociais da escola entre jovens estudantes de escolas públicas no sertão nordestino. 2003. Tese (Doutorado em Educação) - Centro de Educação e Ciências Humanas, Universidade Federal de São Carlos, São Carlos, 2003. 
JODELET, D. Representações sociais: fenômeno, conceito e teoria. In: MOSCOVICI, S. (Dir.). Psicologia social. 2. ed. Paris: P.U.F., 1990.

JODELET, D. Representações sociais: um domínio em expansão. In: JODELET, D. (Org.). As representações sociais. Rio de Janeiro: EdUERJ, 2001. p. 17- 44.

MARIANO, J. M.; SAVAGE, J. Exploring the language of yoth purpose: references to positives states and copyng styles by adolescents with different kinds of purpose. Journal of character education, v.7, n. 1, p. 1-24, 2009.

MARTINS, J. S. A sociabilidade do homem simples: cotidiano e história na modernidade anômala. São Paulo: Editora Contexto, 2008.

MOSCOVICI, S. Introdução: o campo da psicologia social. In: MOSCOVICI, S. (Dir.). Psicologia social. 2. ed. Paris: P.U.F., 1990.

MOSCOVICI, S. Representações sociais: investigações em psicologia. 5. ed. Petrópolis: Vozes, 2007.

OSTI, A.; BRENELLI, R. P. Sentimentos de quem fracassa na escola: análise das representações de alunos com dificuldades de aprendizagem. Psico-USF, Itatiba, v. 18, n. 3, p. 417-426, dez. 2013.

PAIS, J. M. A construção sociológica da juventude: alguns contributos. Revista Análise Social, Lisboa, v. 25, n. 105-106, p. 139-165, 1990.

PEREIRA, F. N.; GARCIA, A. Amizade e escolha profissional: influência ou cooperação?. Revista Brasileira de Orientação Profissional, São Paulo, v. 8, n. 1, p. 71-86, jun. 2007.

PERON, S. I.; GUIMARAES, L. S.; SOUZA, L. K. de. Amizade na adolescência e a entrada na universidade. Estudos e Pesquisas em Psicologia, Rio de Janeiro, v. 10, n. 3, p. 664-681, dez. 2010.

PIOTTO, D. C. A escola e o sucesso escolar: algumas reflexões à luz de Pierre Bourdieu. Revista Vertentes, São João del-Rei, n. 33, p. 48-60, 2009.

PIOTTO, D. C. Universitários de camadas populares em cursos de alta seletividade: aspectos subjetivos. Revista Brasileira de Orientação Profissional, Porto Alegre, v. 11, n. 2, p. 229-242, jul./dez. 2010.

RIBEIRO, D. O que é lugar de fala?. Belo Horizonte: Letramento: Justificando, 2017. 
ROSSI, R. C. A invenção das juventudes - a construção de 'juventude' na Modernidade e o desmoronamento dessa categoria na Pós-Modernidade. Revista Espaço Acadêmico. v. 13, n. 156, p. 147-153, mai. 2014.

SANTOS, R. M. dos; NASCIMENTO, M. A.; MENEZES, J. de A. Os sentidos da escola pública para jovens pobres da cidade do recife. Revista Latinoamericana de Ciencias Sociales, Niñez y Juventud, v. 10, n. 1, p. 289-300, 2012.

SARAIVA, K.; VEIGA-NETO, A. Modernidade líquida, capitalismo cognitivo e educação contemporânea. Educação \& Realidade, v. 34, n. 2, p. 187-201, mai./ago. 2009.

SCHWERTNER, S. F. Palavras e imagens sobre amizade jovem na contemporaneidade. Educação \& Realidade, Porto Alegre, v. 37, n. 1, p. 163-185, jan./abr. 2012.

SOARES, A. B.; MARTINS, J. S. R. Ansiedade dos estudantes diante da expectativa do exame vestibular. Paidéia, Ribeirão Preto, v. 20, n. 45, p. 57-62, abr. 2010.

SOUZA, J. A Construção Social da Subcidadania: para uma Sociologia Política da Modernidade Periférica. Belo Horizonte: Editora UFMG; Rio de Janeiro: IUPERJ, 2003.

SOUZA, J. (Não) Reconhecimento e subcidadania, ou o que é "ser gente"?. Lua Nova: Revista de Cultura e Política, São Paulo, n. 59, p. 51-73, 2003.

SPOSITO, M. P. Juventude: crise, identidade e escola. In: DAYRELL, J. (Org.). Múltiplos olhares sobre educação e cultura. Belo Horizonte: Editora UFMG, 1996. p. 96-104.

\section{DADOS DOS AUTORES}

\section{Francisca Denise Silva Vasconcelos}

Doutora em Sociologia pela Universidade Federal do Ceará. Professora de graduação e pós-graduação da Universidade Federal do Ceará - Campus Sobral e coordenadora do Laboratório de Estudos das Desigualdades \& Diversidades (LAEDDES). denisevasconcelos@ufc.br

\section{Luana Paiva da Silva}

Graduanda em Psicologia pela Universidade Federal do Ceará - Campus Sobral e membro do Laboratório de Estudos das Desigualdades \& Diversidades (LAEDDES). luapaiva@, alu.ufc.br

\section{Jorge Samuel de Sousa Teixeira}

Graduando em Psicologia pela Universidade Federal do Ceará - Campus Sobral e membro do Laboratório de Estudos das Desigualdades \& Diversidades (LAEDDES).jorgesamuel@, alu.ufc.br 


\section{Bárbara Ellen Viana Sales}

Graduanda em Psicologia pela Universidade Federal do Ceará - Campus Sobral e membro do Laboratório de Estudos das Desigualdades \& Diversidades (LAEDDES). bellenjys@ alu.ufc.br

\section{Gracymara Mesquita Severiano}

Mestranda em Psicologia e Políticas Públicas pela Universidade Federal do Ceará - Campus Sobral e membro do Laboratório de Estudos das Desigualdades \& Diversidades (LAEDDES).gracymesquita@hotmail.com

\section{Juliana Maria do Nascimento Mota}

Mestranda em Psicologia e Políticas Públicas pela Universidade Federal do Ceará - Campus Sobral e membro do Laboratório de Estudos das Desigualdades \& Diversidades (LAEDDES).julianamemota@gmail.com

Submetido em: 23-10-2020

Aceito em: 28-02-2021 